\title{
鉱物の $\mathrm{OH}$ イオンの力の定数と核間距離
}

\author{
Force Constant and Internuclear Distance of \\ $\mathrm{OH}$ Ions in Minerals
}

大 森 啓 一 (Keiichi Omori)*

\section{$\mathrm{OH}$ イオンの実測波数とカの定数}

2 原子分子の位置エネルギー $(V)$ は原子核間距離 $(\boldsymbol{r})$ の関数で, これは Morse 関数と呼ばれ, 次式で示される（Herzberg 1950, 町田勝之輔1965, 島内武彦 1968)。

$$
V(r)=D\left\{1-e^{-a\left(r-r_{e}\right) / r_{e}}\right\}^{2}
$$

ここに，Dは解離エネルギー, $a$ は曲率に関する定数, 又 $r_{e}$ は平衡原子核 間距離, 即ち $V(\boldsymbol{r})$ が極小值の時の $\boldsymbol{r}$ の值である。

この曲線は近似的汇同じ曲率の放物線で示され, 展開式は 3 次以上の項を 省略した次式となる。

$$
V(\boldsymbol{r})=V\left(\boldsymbol{r}_{e}\right)+\frac{d V\left(\boldsymbol{r}_{e}\right)}{d r}\left(\boldsymbol{r}-\boldsymbol{r}_{e}\right)+\frac{1}{2} \frac{d^{2} V\left(\boldsymbol{r}_{e}\right)}{d r^{2}}\left(\boldsymbol{r}-\boldsymbol{r}_{e}\right)^{2}
$$

ここに右辺の第 1 及び第 2 項は 0 となるので, 第 3 項の係数を $d^{2} V\left(r_{e}\right) / d r^{2}$ $=k$ 及び $\left(\boldsymbol{r}-r_{\mathbf{0}}\right)=q$ とすると, $V(\underline{q})=\frac{1}{2} k q^{2}$ を得る。

これは原子核が核間距離の変化 $q$ に比例する $-k q$ の力をうけて運動する ことを意味し, こてにkは力の定数, 又位置エネルギー曲線の平衡位置付近 の曲率である。

正確な力の定数を求めるためには，(1)式で省略した 3 次及び 4 次の項を含 む位置エネルギーを用いて, 波動方程式からエネルギー固有值 $E v$ を求める。 この固有値は非調和項を含んでいる。即ち

$$
E v=h \nu_{e}\left(v+\frac{1}{2}\right)-h \nu_{e} x_{e}\left(v+\frac{1}{2}\right)^{2}
$$

\footnotetext{
* 東北大学理学部岩石鉱物鉱床学教室
} 
第 1 表 $\mathrm{OH}$ イオンの波数 $\left(\mathrm{cm}^{-1}\right)$ と力の定数 (md/ $\AA$ ) の対照表

\begin{tabular}{|c|c|c|c|c|c|c|c|c|c|c|}
\hline $\mathrm{cm}^{-1}$ & 0 & 1 & 2 & 3 & 4 & 5 & 6 & 7 & 8 & 9 \\
\hline $\begin{array}{l}3200 \\
3210 \\
3220 \\
3230 \\
3240 \\
3250 \\
3260 \\
3270 \\
3280 \\
3290\end{array}$ & $\begin{array}{l}6.2563 \\
6.2954 \\
6.3347 \\
6.3741 \\
6.4137 \\
6.4533 \\
6.4931 \\
6.5330 \\
6.5730 \\
6.6131\end{array}$ & $\begin{array}{l}2602 \\
2994 \\
3387 \\
3781 \\
4176 \\
4573 \\
4971 \\
5370 \\
5770 \\
6172\end{array}$ & $\begin{array}{l}2641 \\
3033 \\
3426 \\
3820 \\
4216 \\
4613 \\
5011 \\
5410 \\
5810 \\
6212\end{array}$ & $\begin{array}{l}2680 \\
3072 \\
3465 \\
3860 \\
4255 \\
4652 \\
5050 \\
5450 \\
5850 \\
6252\end{array}$ & $\begin{array}{l}2719 \\
3111 \\
3505 \\
3899 \\
4295 \\
4692 \\
5090 \\
5490 \\
5890 \\
6292\end{array}$ & $\begin{array}{l}2758 \\
3151 \\
3544 \\
3939 \\
4335 \\
4732 \\
5130 \\
5530 \\
5931 \\
6333\end{array}$ & $\begin{array}{l}2798 \\
3190 \\
3584 \\
3978 \\
4374 \\
4772 \\
5170 \\
5570 \\
5971 \\
6373\end{array}$ & $\begin{array}{l}2837 \\
3229 \\
3623 \\
4018 \\
4414 \\
4811 \\
5210 \\
5610 \\
6011 \\
6413\end{array}$ & $\begin{array}{l}2876 \\
3269 \\
3662 \\
4057 \\
4454 \\
4851 \\
5250 \\
5650 \\
6051 \\
6453\end{array}$ & $\begin{array}{l}2915 \\
3308 \\
3702 \\
4097 \\
4493 \\
4891 \\
5290 \\
5690 \\
6091 \\
6494\end{array}$ \\
\hline $\begin{array}{l}3300 \\
3310 \\
3320 \\
3330 \\
3340 \\
3350 \\
3360 \\
3370 \\
3380 \\
3390\end{array}$ & $\begin{array}{l}6.6534 \\
6.6938 \\
6.7343 \\
6.7749 \\
6.8157 \\
6.8566 \\
6.8975 \\
6.9387 \\
6.9799 \\
7.0213\end{array}$ & $\begin{array}{l}6574 \\
6978 \\
7384 \\
7790 \\
8198 \\
8606 \\
9017 \\
9428 \\
9840 \\
0254\end{array}$ & $\begin{array}{l}6615 \\
7019 \\
7424 \\
7831 \\
8238 \\
8647 \\
9058 \\
9469 \\
9882 \\
0296\end{array}$ & $\begin{array}{l}6655 \\
7059 \\
7465 \\
7871 \\
8279 \\
8688 \\
9099 \\
9510 \\
9923 \\
0337\end{array}$ & $\begin{array}{l}6695 \\
7100 \\
7505 \\
7912 \\
8320 \\
8729 \\
9140 \\
9551 \\
9964 \\
0378\end{array}$ & $\begin{array}{l}6736 \\
7140 \\
7546 \\
7953 \\
8361 \\
8770 \\
9181 \\
9593 \\
0006 \\
0420\end{array}$ & $\begin{array}{l}6776 \\
7181 \\
7587 \\
7994 \\
8402 \\
8811 \\
9222 \\
9634 \\
0047 \\
0461\end{array}$ & $\begin{array}{l}6817 \\
7221 \\
7627 \\
8034 \\
8443 \\
8852 \\
9263 \\
9675 \\
0088 \\
0503\end{array}$ & $\begin{array}{l}6857 \\
7262 \\
7668 \\
8075 \\
8484 \\
8893 \\
9304 \\
9716 \\
0130 \\
0544\end{array}$ & $\begin{array}{l}6897 \\
7302 \\
7709 \\
8116 \\
8525 \\
8934 \\
9345 \\
9758 \\
0171 \\
0586\end{array}$ \\
\hline $\begin{array}{l}3400 \\
3410 \\
3420 \\
3430 \\
3440 \\
3450 \\
3460 \\
3470 \\
3480 \\
3490\end{array}$ & $\begin{array}{r}7.0628 \\
7.1044 \\
7.1461 \\
7.1879 \\
7.2299 \\
7.2720 \\
7.3142 \\
7.3566 \\
7.3990 \\
7.4416\end{array}$ & $\begin{array}{l}0669 \\
1085 \\
1503 \\
1921 \\
2341 \\
2762 \\
3185 \\
3608 \\
4033 \\
4459\end{array}$ & $\begin{array}{l}0711 \\
1127 \\
1544 \\
1963 \\
2383 \\
2804 \\
3227 \\
3650 \\
4075 \\
4501\end{array}$ & $\begin{array}{l}0752 \\
1169 \\
1586 \\
2005 \\
2425 \\
2847 \\
3269 \\
3693 \\
4118 \\
4544\end{array}$ & $\begin{array}{l}0794 \\
1210 \\
1628 \\
2047 \\
2467 \\
2889 \\
3311 \\
3735 \\
4160 \\
4587\end{array}$ & $\begin{array}{l}0835 \\
1252 \\
1670 \\
2089 \\
2509 \\
2931 \\
3354 \\
3378 \\
4203 \\
4629\end{array}$ & $\begin{array}{l}0877 \\
1294 \\
1712 \\
2131 \\
2552 \\
2973 \\
3396 \\
3820 \\
4246 \\
4672\end{array}$ & $\begin{array}{l}0919 \\
1336 \\
1754 \\
2173 \\
2594 \\
3015 \\
3439 \\
3863 \\
4288 \\
4715\end{array}$ & $\begin{array}{l}0960 \\
1377 \\
1796 \\
2215 \\
2636 \\
3058 \\
3481 \\
3905 \\
4331 \\
4758\end{array}$ & $\begin{array}{l}1002 \\
1419 \\
1837 \\
2257 \\
2678 \\
3100 \\
3523 \\
3948 \\
4373 \\
4800\end{array}$ \\
\hline $\begin{array}{l}3500 \\
3510 \\
3520 \\
3530 \\
3540 \\
3550 \\
3560 \\
3570 \\
3580 \\
3590\end{array}$ & $\begin{array}{l}7.4843 \\
7.5271 \\
7.5701 \\
7.6132 \\
7.6564 \\
7.6997 \\
7.7431 \\
7.7867 \\
7.8304 \\
7.8742\end{array}$ & $\begin{array}{l}4886 \\
5314 \\
5744 \\
6175 \\
6607 \\
7040 \\
7475 \\
7910 \\
8347 \\
8786\end{array}$ & $\begin{array}{l}4929 \\
5357 \\
5787 \\
6218 \\
6650 \\
7084 \\
7518 \\
7954 \\
8391 \\
8830\end{array}$ & $\begin{array}{l}4972 \\
5400 \\
5830 \\
6261 \\
6693 \\
7127 \\
7562 \\
7998 \\
8435 \\
8873\end{array}$ & $\begin{array}{l}5014 \\
5443 \\
5873 \\
6304 \\
6737 \\
7170 \\
7605 \\
8041 \\
8479 \\
8917\end{array}$ & $\begin{array}{l}5057 \\
5486 \\
5916 \\
6348 \\
6780 \\
7214 \\
7649 \\
8085 \\
8523 \\
8961\end{array}$ & $\begin{array}{l}5100 \\
5529 \\
5959 \\
6391 \\
6823 \\
7257 \\
7692 \\
8129 \\
8566 \\
9005\end{array}$ & $\begin{array}{l}5143 \\
5572 \\
6002 \\
6434 \\
6867 \\
7301 \\
7736 \\
8173 \\
8610 \\
9049\end{array}$ & $\begin{array}{l}5286 \\
5615 \\
6045 \\
6477 \\
6910 \\
7344 \\
7780 \\
8216 \\
8654 \\
9093\end{array}$ & $\begin{array}{l}5229 \\
5658 \\
6089 \\
6520 \\
6953 \\
7388 \\
7823 \\
8260 \\
8698 \\
9137\end{array}$ \\
\hline $\begin{array}{l}3600 \\
3610 \\
3620 \\
3630 \\
3640 \\
3650 \\
3660 \\
3670 \\
3680 \\
3690\end{array}$ & $\begin{array}{l}7.9181 \\
7.9622 \\
8.0063 \\
8.0506 \\
8.0950 \\
8.1396 \\
8.1842 \\
8.2290 \\
8.2739 \\
8.3190\end{array}$ & $\begin{array}{l}9225 \\
9666 \\
0108 \\
0551 \\
0995 \\
1440 \\
1887 \\
2335 \\
2784 \\
3235\end{array}$ & $\begin{array}{l}9269 \\
9710 \\
0152 \\
0595 \\
1039 \\
1485 \\
1932 \\
2380 \\
2829 \\
3280\end{array}$ & $\begin{array}{l}9313 \\
9754 \\
0196 \\
0639 \\
1084 \\
1530 \\
1977 \\
2425 \\
2874 \\
3325\end{array}$ & $\begin{array}{l}9357 \\
9798 \\
0240 \\
0684 \\
1128 \\
1574 \\
2021 \\
2470 \\
2919 \\
3370\end{array}$ & $\begin{array}{l}9401 \\
9842 \\
0285 \\
0728 \\
1173 \\
1619 \\
2066 \\
2515 \\
2964 \\
3415\end{array}$ & $\begin{array}{l}9445 \\
9886 \\
0329 \\
0773 \\
1217 \\
1664 \\
2111 \\
2560 \\
3009 \\
3460\end{array}$ & $\begin{array}{l}9489 \\
9931 \\
0373 \\
0817 \\
1262 \\
1708 \\
2156 \\
2604 \\
3054 \\
3505\end{array}$ & $\begin{array}{l}9533 \\
9975 \\
0418 \\
0861 \\
1307 \\
1753 \\
2201 \\
2649 \\
3099 \\
3551\end{array}$ & $\begin{array}{l}9577 \\
0019 \\
0462 \\
0906 \\
1351 \\
1798 \\
2245 \\
2694 \\
3144 \\
3596\end{array}$ \\
\hline $\begin{array}{l}3700 \\
3710 \\
3720 \\
3730 \\
3740 \\
3750 \\
3760 \\
3770 \\
3780 \\
3790 \\
3800\end{array}$ & $\begin{array}{l}8.3641 \\
8.4094 \\
8.4548 \\
8.5003 \\
8.5459 \\
8.5917 \\
8.6376 \\
8.6836 \\
8.7297 \\
8.7760 \\
8.8223\end{array}$ & $\begin{array}{l}3686 \\
4139 \\
4593 \\
5049 \\
5505 \\
5963 \\
6422 \\
6882 \\
7343 \\
7806 \\
8270\end{array}$ & $\begin{array}{l}3732 \\
4184 \\
4639 \\
5094 \\
5551 \\
6009 \\
6568 \\
6928 \\
7389 \\
7852 \\
8316\end{array}$ & $\begin{array}{l}3777 \\
4230 \\
4684 \\
5140 \\
5596 \\
6054 \\
6514 \\
6974 \\
7436 \\
7899 \\
8363\end{array}$ & $\begin{array}{l}3822 \\
4275 \\
4730 \\
5185 \\
5642 \\
6100 \\
6560 \\
7020 \\
7482 \\
7945 \\
8409\end{array}$ & $\begin{array}{l}3867 \\
4321 \\
4775 \\
5231 \\
5688 \\
6146 \\
6606 \\
7066 \\
7528 \\
7991 \\
8456\end{array}$ & $\begin{array}{l}3913 \\
4366 \\
4821 \\
5277 \\
5734 \\
6192 \\
6652 \\
7112 \\
7574 \\
8038 \\
8502\end{array}$ & $\begin{array}{l}3958 \\
4411 \\
4866 \\
5322 \\
5780 \\
6238 \\
6698 \\
7159 \\
7621 \\
8084 \\
8549\end{array}$ & $\begin{array}{l}4003 \\
4457 \\
4912 \\
5368 \\
5825 \\
6284 \\
6744 \\
7205 \\
7667 \\
8130 \\
8595\end{array}$ & $\begin{array}{l}4048 \\
4502 \\
4957 \\
5414 \\
5871 \\
6330 \\
6790 \\
57251 \\
7713 \\
7177 \\
58642\end{array}$ \\
\hline
\end{tabular}


ここにンは振動数, $v$ は振動量子数, 又 $x_{e}$ は非調和定数である。

これより, 量子数 $v=0$ の基底状態と $v=1$ の励起状態との間の遷移に対 する振動数として,

$$
\nu_{0}=\frac{1}{h}\left(E_{1}-E_{0}\right)=\nu_{e}\left(1-2 x_{e}\right)
$$

を得る。

ここに $\nu_{0}$ は実測された振動数, 又 $\nu_{e}$ は基準振動の振動数である。乙れ より $\nu_{0}$ を非調和定数 $x_{e}$ で補正した $\nu_{e}$ を用いて, 2 原子分子の力の定数が 求められる。

今, $\mathrm{OH}$ イオンの赤外吸収帯の実測波数 3200 乃至 $3809 \mathrm{~cm}^{-1}$ 間について, 各力の定数 (md $/ \AA$ ) を算出すると，第 1 表のようになる。乙れから，各種 鉱物中の $\mathrm{OH}$ イオンの力の定数が容易に求められる。

\section{OH イオンの原子核間距離}

2 原子分子の力の定数と核間距離の関係式は種々発表されているが, Badger (1935) の式が広く用いられている。これによって力の定数からO$\mathrm{H}$ 核間距離を算出することができる。

\section{実例 Sideronatrite}

Chile, San Simon 鉱山産 sideronatrite $\mathrm{Na}_{2} \mathrm{Fe}\left(\mathrm{SO}_{4}\right)_{2}(\mathrm{OH}) \cdot 3 \mathrm{H}_{2} \mathrm{O}$ の赤 外吸収スペクトルでは，第 1 困に示したように, $\mathrm{OH}$ イオンと $\mathrm{H}_{2} \mathrm{O}$ 分子の 吸収帯が現われている。ととに縦軸は吸収率である。

これらの吸収帯について, 波数, 吸収率, 力の定数及び O-H 核間距離を

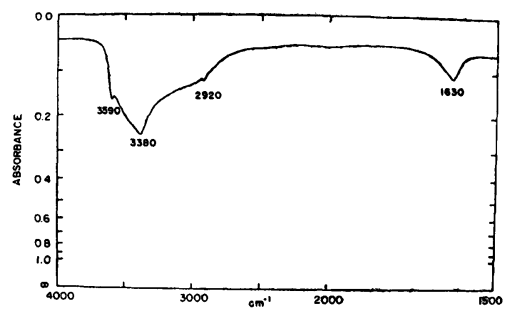

第 1 国 Sideronatrite の赤外吸収スペクトル 
示すと，次のようになる。

波数 $\left(\mathrm{cm}^{-1}\right)$ 吸収率

力の定数 $(\mathrm{md} / \AA \AA \AA) \quad \mathrm{O}-\mathrm{H}$ 核間距離 $(\AA)$

$\begin{array}{lllll}3590 & 0.16 & \nu(\mathrm{OH}) & \mathrm{K}=7.87 & 0.96\end{array}$

$3380 \quad 0.25$

2920

0.12

1630

0.11

$\left.\begin{array}{l}\nu_{3} \\ \nu_{1} \\ \nu_{2}\end{array}\right\}\left(\mathrm{H}_{2} \mathrm{O}\right)\left\{\begin{array}{l}\mathrm{K}=6.00 . \\ \mathrm{H}=1.60 \\ \mathrm{~F}=-1.40\end{array}\right\}$

1.01

OH イオンの吸収帯 伸縮振動吸収帯 $\nu=3590 \mathrm{~cm}^{-1}$ について, 第 1 表か ら力の定数を求めると $\mathrm{K}=7.87 \mathrm{md} / \AA$, 又との力の定数から $\mathrm{O}-\mathrm{H}$ 核間距離 を算出すると $r_{e}=0.96 \AA$ となる。

$\mathbf{H}_{2} \mathbf{O}$ の吸収帯 3 つの吸収帯 $\nu_{1}=2920, \nu_{2}=1630, \nu_{3}=3380 \mathrm{~cm}^{-1}$ があ る。 $\nu_{1}$ は対称伸縮振動, $\nu_{2}$ は変角振動, 又 $\nu_{3}$ は逆対称伸縮振動で, これら は総て選択律から赤外活性である。 $\mathrm{H}_{2} \mathrm{O}$ 分子の原子価角は $90^{\circ}$ より大きいの で, $\nu_{3}>\nu_{1}$ となる。乙の比 $\nu_{3} / \nu_{1}=1.157$ が気体の $\mathrm{H}_{2} \mathrm{O}$ の比 1.028 より大 きいのは力の定数の異なるためである。 $\mathrm{GF}$ 行列法でこの力の定数を求める と, $\mathrm{K}=6.00, \mathrm{H}=1.60, \mathrm{~F}=-1.40 \mathrm{md} / \AA$ となり，乙れより $\mathrm{O}-\mathrm{H}$ 核間距 離として $r_{e}=1.01 \AA$ を得る。

乙れを別に，Nakagawa et al. (1955) 飞従って水素結合間距離(O-H O) を求めると $2.70 \AA$, 更に Lippincott et al. (1955) 亿従って O-H 距 離を求めると $1.02 \AA$ となり，上記とほぼ一致する。

一般に水素結合 $(\mathrm{O}-\mathrm{H} \cdots \mathrm{O})$ のプロトンの位置は結合の強さに応じて変化 し, 赤外吸収帯の波数も変化する。比較のため一例を示すと, セッコウの $\mathrm{H}_{2} \mathrm{O}$ では $\mathrm{O}-\mathrm{H}=1.002 \AA$ 及び $0.981 \AA$, 又 $\mathrm{H}_{2} \mathrm{O}$ と $\mathrm{SO}_{4}$ のOの水素結合間 距離は $\mathrm{O}-\mathrm{H} \cdots \mathrm{O}=2.816 \AA$ 及び $2.824 \AA$ である (Atoji and Rundle 1958)。 Sideronatrite の結晶構造及び中性子回折の結果は未だ発表されていないが, $\mathrm{O}-\mathrm{H}$ 距離は上記に近いであろう。

この研究を僫浔された東京大学鉱物学教室竹内慶夫博士並びに計算でお世 話になった東北大学大型計算機センターに対して厚く感謝する。（1970年 7 月 2 日受理)

文献

1) Atoji, M. and R.E. Rundle (1958) J. Chem. Phys. 29, 1306-1311.

2) Badger, R. M. (1935) J. Chem. Phys. 3, 710-714.

3) Herzberg, G. (1950) Molecular Spectra and Molecular Structure I, 1-658. 
4) Lippincott, E. R. and R. Schroeder (1955) J. Chem. Phys. 23, 1099-1106.

5) 町田勝之輔 (1965) 赤外・ラマンスペクトルの解釈 1-130.

6) Nakagawa, K., M. Margoshes and R. E. Rundle (1955) J. Am. Chem. Soc. 77, 6480-6486.

7）島内武彦 (1968) 分子力場と力の定数, 化学の領域 増刊 85 号 35-63. 